\title{
UWB U- Shaped Planar Printed Antenna Loaded with L- Slot and Tuning Stubs
}

\author{
M. Neelaveni Ammal', B. Ramachandran ${ }^{2}$, P. H. Rao ${ }^{3}$ \\ 1,2 Department of Electronics \& Communication Engineering, SRM University, Chennai-603203, India \\ ${ }^{3}$ Senior Member - IEEE, SAMEER, Center for Electro Magnetics, Chennai-600113, India \\ (neelaveni.m \& ramachandran.b\}@ktr.srmuniv.ac.in, phrao@cem.sameer.gov.in
}

\begin{abstract}
This paper presents an UWB planar printed compact monopole antenna comprising of U-shaped notch loaded with L-slot and tuning stubs. It has a partial ground plane to achieve an excellent impedance matching to increase the impedance bandwidth. The simulated results show that the proposed antenna exhibit UWB for $3.84 \mathrm{GHz}$ to $11.61 \mathrm{GHz}$ with $-10 \mathrm{~dB}$ return loss and VSWR $<2$. Antenna gain and radiation pattern plots for different frequencies are also investigated. The performance characteristics of the proposed antenna are simulated using Ansoft HFSS software. plane.

Index Terms - planar antenna, ultra wideband, partial ground
\end{abstract}

\section{INTRODUCTION}

The Federal Communications Commission (FCC)[1] regularized rules for the commercial use of Ultra wideband systems, operating in the frequency range of $3.1 \mathrm{GHz}$ to 10.6 $\mathrm{GHz}$. Ultra wideband systems offer attractive features such as large bandwidth, transmission of high data rates, immunity to multipath interference, low power consumption and simple configuration [2]. Because of these attractive features, the researches on ultra wideband systems have been increasing fastly.

With the fast growing interest in the area of wireless communication systems, the challenging aspect is designing Miniaturized antennas. Planar printed antennas have been preferred for ultra wideband applications because of the features of small size, light weight, low profile, low cost and compatibility with integrated circuits [3]-[4].

Reviewing the literature shows various methods can be used to enhance the impedance bandwidth. Those methods include cutting slots on the patch, putting parasitic patches near the radiator, embedding a quarter wavelength tuning stub within a slot on the patch and inserting a slit on the patch. In [5] - [9], different planar antennas with microstrip line feeding for ultra wideband applications are presented. In some cases, U-slot is reported [10]-[11]. In [12], antenna is fed by CPW .

In this paper, a new planar printed antenna for UWB applications is proposed. A new technique has been reported by introducing tuning stubs along with the U- shaped radiating element. The antenna consists of L-shaped slot to provide significant impedance bandwidth.

This paper is organized as below. Section II presents the geometry of the proposed antenna. In Section III, results are discussed and Section IV concludes the paper.

\section{ANTENNA GEOMETRY}

The geometry of the proposed antenna with its dimensional parameters is illustrated in Fig. 1. The antenna is located in xy plane and the normal direction is parallel to $\mathrm{z}$ axis. Based on the dimensions mentioned in Table I, the antenna is designed on RT/ Duroid 5870 substrate with a relative permittivity $\left(\xi_{\mathrm{r}}\right)$ of 2.33 , Loss Tangent $(\tan \delta)$ of 0.0012 , thickness of $0.7 \mathrm{~mm}$ and ground plane width of $5.2 \mathrm{~mm}$. The U-shaped radiating patch consists of L-shaped slot that is fed by microstrip line.

Table I Geometrical dimensions of the proposed antenna

\begin{tabular}{|c|c|c|c|}
\hline parameter & value(mm) & parameter & value(mm) \\
\hline $\mathrm{a}$ & 24 & 1 & 1 \\
\hline $\mathrm{b}$ & 28 & $\mathrm{~m}$ & 11.1 \\
\hline $\mathrm{c}$ & 5 & $\mathrm{n}$ & 1.7 \\
\hline $\mathrm{d}$ & 2 & $\mathrm{p}$ & 6 \\
\hline $\mathrm{e}$ & 2.85 & $q$ & 5 \\
\hline $\mathrm{f}$ & 5 & w & 5.2 \\
\hline $\mathrm{g}$ & 5 & $\mathrm{~h}$ & 0.7 \\
\hline $\mathrm{i}$ & 2.65 & $\mathrm{~s}$ & 3 \\
\hline $\mathrm{j}$ & 3 & $\mathrm{t}$ & 1.5 \\
\hline $\mathrm{k}$ & 1.1 & & \\
\hline
\end{tabular}




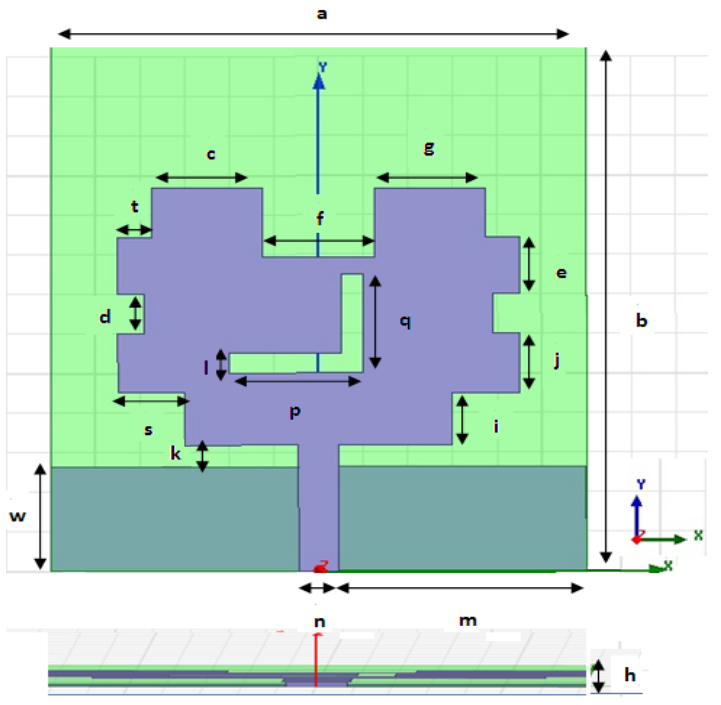

Fig. 1 Antenna geometry of the proposed antenna

\section{RESULTS AND DISCUSSION}

One of the important parameters in the design of antenna is the size of the ground plane, because the bandwidth is heavily dependent on the ground plane size. The return loss of the antenna improves gradually when the length of the ground patch reduces gradually and good result is obtained.

The goal of the proposed antenna design is to achieve good performance in the return loss. The simulated result of return loss shows that the center frequency of bandwidth at $7.72 \mathrm{GHz}$ and the bandwidth at $-10 \mathrm{~dB}$ ranging from $3.84 \mathrm{GHz}$ to $11.61 \mathrm{GHz}$ as shown in Fig. 2. To achieve this, suitable antenna geometry is needed. Thus the antenna design parameters such as patch shape, slot, size of the tuning stubs and width of the feed are investigated to obtain good return loss and impedance bandwidth. The variation of VSWR with frequency as depicted in Fig. 3 indicates that an excellent matching between antenna and feedline. The VSWR is less than 2 over the entire bandwidth.

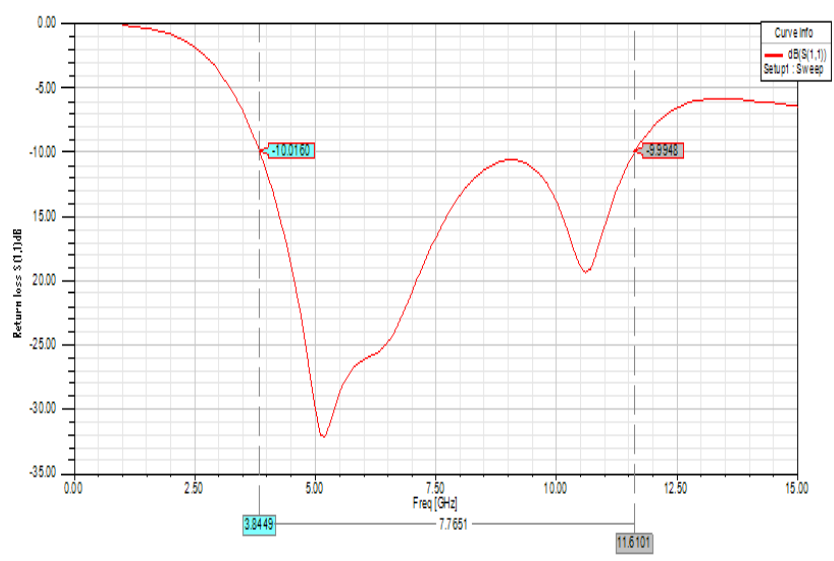

Fig. 2 Simulated return loss curve for the proposed antenna

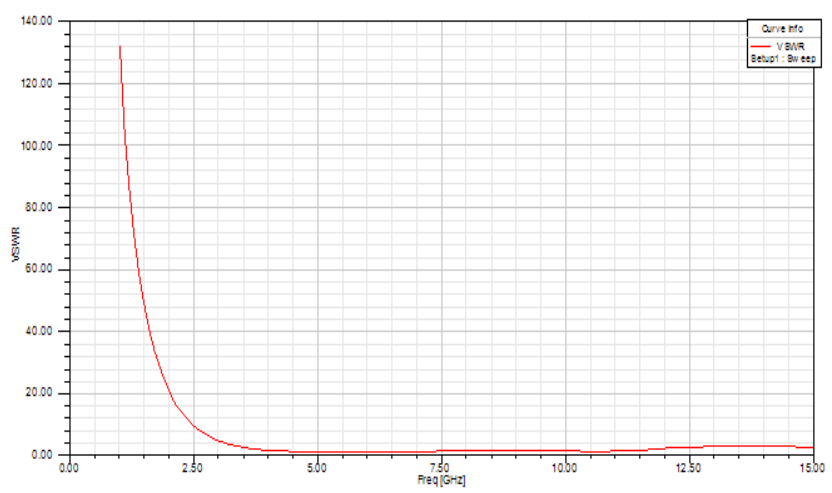

Fig. 3 Simulated VSWR curve of the proposed antenna

Fig. 4 shows three dimensional radiation pattern of the proposed antenna. Fig. 5 shows gain of the proposed antenna. The gain varies upto $3.22 \mathrm{dBi}$. The simulated radiation patterns of the proposed antenna in H-Plane and E-Plane at $4.2 \mathrm{GHz}$, $7.5 \mathrm{GHz}$ and $10 \mathrm{GHz}$ are depicted in Fig. $6 \mathrm{a}$ and $6 \mathrm{~b}$. From the radiation pattern diagrams, it is observed that in H-plane, radiation pattern is Omni directional in the lower frequencies of UWB range and it is distorted in higher frequencies. In E-plane, the pattern is bidirectional.
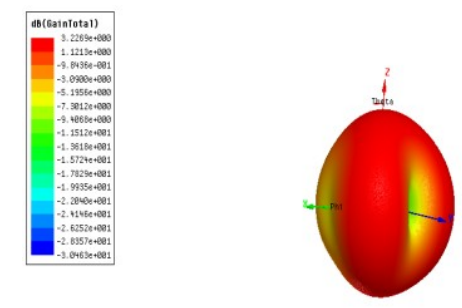

Fig. 4 Simulated 3D radiation pattern of the proposed antenna

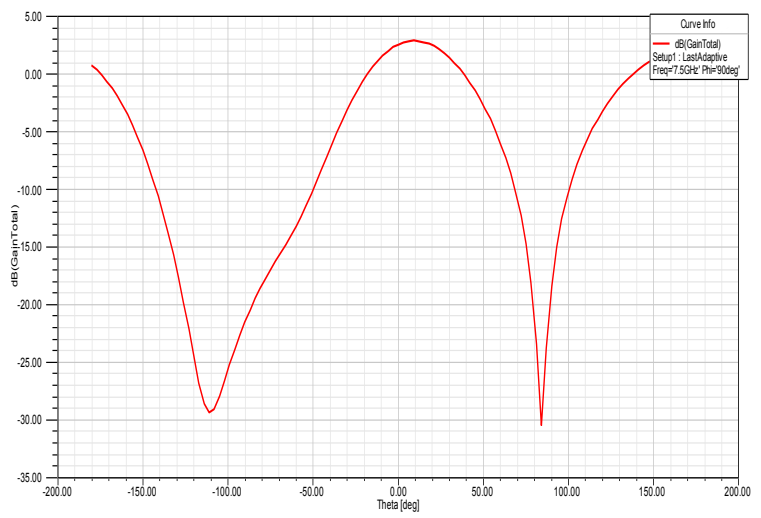

Fig. 5 Simulated gain curve for the proposed antenna 


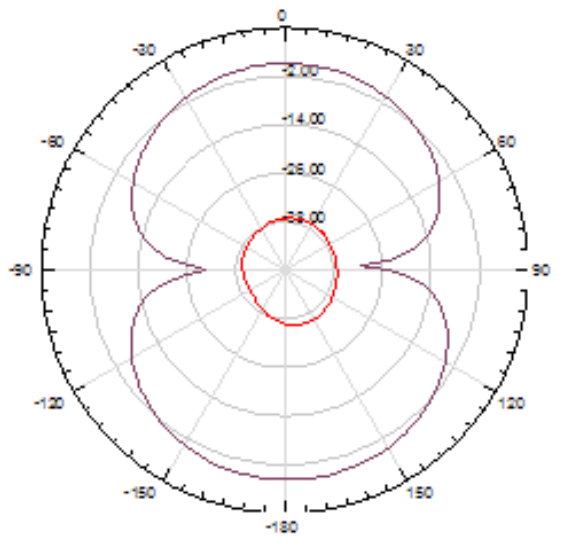

(i)

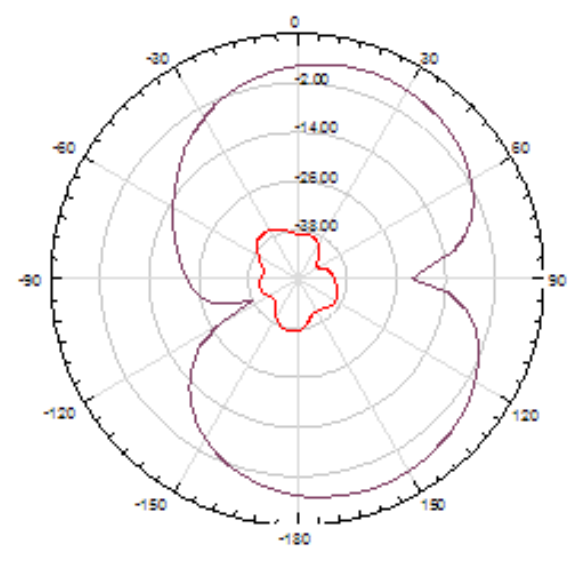

(ii)

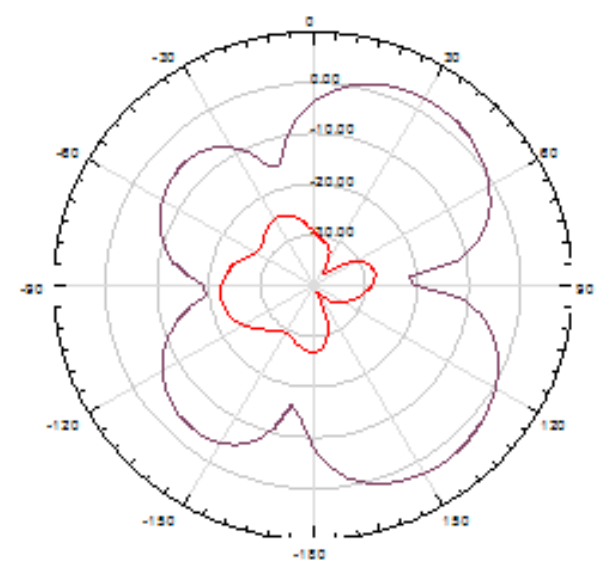

(iii)

Fig. 6a E-Plane radiation pattern at (i) $4.2 \mathrm{GHz}$ (ii) $7.5 \mathrm{GHz}$ (iii) $10 \mathrm{GHz}$

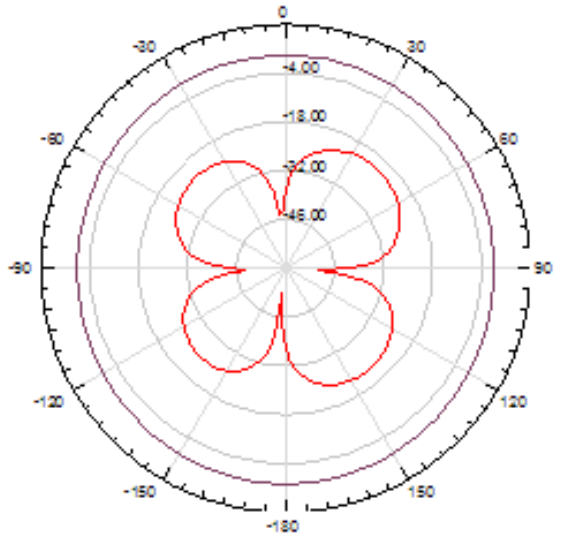

(iv)

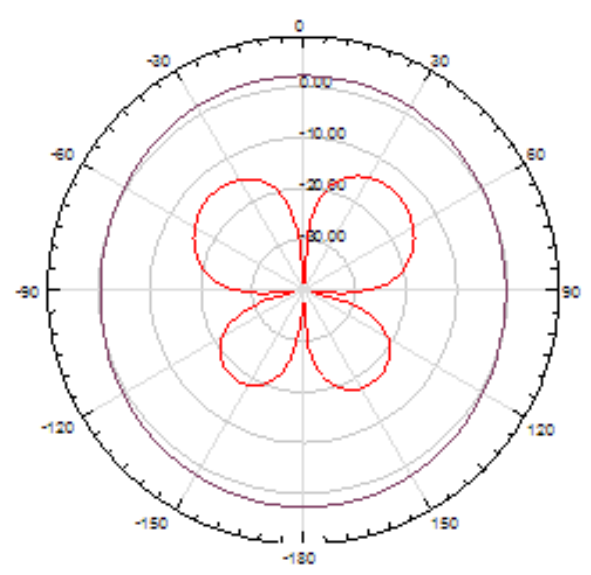

(v)

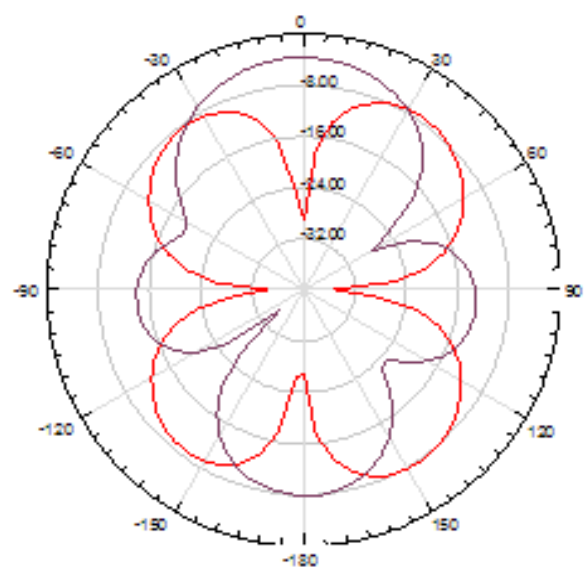

(vi)

Fig. 6b H-Plane radiation pattern at (iv) $4.2 \mathrm{GHz}$ (v) $7.5 \mathrm{GHz}$ (vi) $10 \mathrm{GHz}$ 


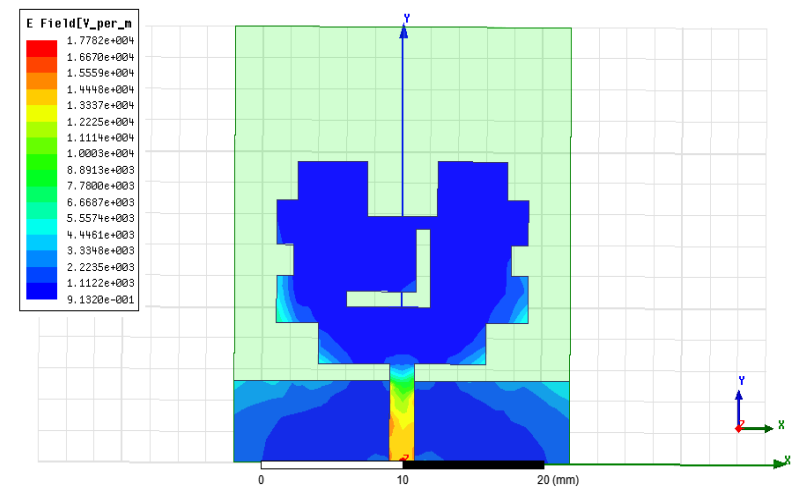

Fig. 7 Simulated electric current distribution of the proposed antenna

The simulated electric current distribution on the ground plane and radiating element are illustrated in Fig. 7. Electric current is distributed in the upper part of ground plane and in the lower portion of the radiating element along with the junction location of tuning stubs. From the diagram, it is clear that the upper part of ground plane is also considered as a radiating element.

\section{CONCLUSION}

A new UWB planar printed antenna with simple structure and low profile has been proposed. Based on the results simulated using Ansoft HFSS, the frequency range obtained for $-10 \mathrm{~dB}$ is 3.84 to $11.61 \mathrm{GHz}$ and VSWR < 2. The simulated $-10 \mathrm{~dB}$ return loss shows that the proposed antenna achieves impedance bandwidth ranging from $3.84 \mathrm{GHz}$ to $11.61 \mathrm{GHz}$ and the gain is about $3.22 \mathrm{dBi}$. The E-Plane and $\mathrm{H}-$ Plane radiation patterns at $4.2,7.5$ and $10 \mathrm{GHz}$ are presented.
The proposed antenna presents Omni directional radiation pattern in the H-Plane. The presented results show that the proposed antenna is suitable for UWB applications.

\section{REFERENCES}

[1] FCC, First report and order on Ultra wideband Technology, 2002.

[2] Jeffrey H. Reed, "An introduction to Ultra wideband communication Systems," Communication Engineering and Emerging Technologies Series, Prentice Hall, 2005.

[3] Ramesh Garg, Prakash Bhartia, Inder Bahl, Apisak Ittipiboon, "Microstrip Antenna Design Handbook," ARTECH House, 2001

[4] J.R. James, P.S. Hall, "Handbook of Microstrip Antennas," vol. 2, IEEE EM wave series 28, Peter Perigrinus Ltd, 1989.

[5] J. Jung, W. Choi, and J. Choi, "A Small Wideband Microstrip fed Monopole antenna", IEEE Microwave and Wireless Components Letters, vol.15, No.10, pp. 703-705, Mar. 2008.

[6] K. H. Kim, Y. J. Cho, S. H. Hwang and S. O. Park, "Band notched UWB Planar monopole antenna with two Parasitic patches", Electronics Letters vol.41, No. 14, pp. 783-785, July 2005.

[7] W. Choi, J. Jung, K. Chung and J. Choi, "Compact Microstrip fed Antenna with band stop characteristic for Ultra wideband Applications", Microwave and Optical Technology Letters, vol.47, No.1, Oct. 2005.

[8] K. Chung, J. Kim, and J. Choi, "Wideband Microstrip fed Monopole having Frequency Band-Notch Function”, IEEE Microwave and Wireless Components Letters, vol.15, No.11, 2005.

[9] J. Choi, K. Chung and Y. Roh, "Parametric Analysis of a Band-Rejection Antenna for UWB Application", Microwave and Optical Technology Letters, vol. 47, No. 3, Nov. 2005.

[10] K. F. Lee, K. M. Luk, K. F. Tong, Y. L. Yung, T. Huynh, "Experimental study of the rectangular patch with a U-Shaped slot", IEEE, 1996.

[11] Mohamed Hassanien, Ehab K.I. Hamad, "Compact Rectangular UShaped slot Microstrip patch antenna for UWB applications", Middle East Conference on Antennas and propagation (MECAP), Cairo, Egypt, IEEE - APS, 2010

[12] M. Koohestani, M. Golpour, "U-Shaped Microstrip patch antenna with Novel parasitic tuning stubs for UWB applications," IET Transactions on Microwave Antenna Propagation, vol. 4, No. 7, pp. $938-940,2010$ 